(Kennedy, I953). The hypothalamic disorder, in fact, is not primarily of appetite, it is of long-term energy balance.

\title{
REFERENCES
}

Adey, W. R. (1957). Reticular Formation of the Brain. London: J. and A. Churchill.

Adolph, E. F. (1947). Amer. F. Physiol. r5I, I Io.

Anand, B. K., Dua, S. \& Chhina, G. C. (1958). Indian F. med. Res. 46, 277.

Brobeck, J. R. (1946). Physiol. Rev. 26, 54r.

Brobeck, J. R., Wheatland, M. \& Strominger, J. L. (1947). Endocrinology, 40, 65.

Brooks, C. McC. (1946). Fed. Proc. 5, 12.

Bruce, H. M. \& Kennedy, G. C. (1951). Proc. Soc. Stud. Fertil. 3, 24.

Hamburger, W. W. (r960). Amer. F. clin. Nutr. 8, 569.

Hetherington, A. W. \& Ranson, S. W. (1940). Anat. Rec. 78, I49.

Hetherington, A. W. \& Ranson, S. W. (1942). Amer. J. Physiol. 136, 6o9.

Johnson, M. L., Burke, B. S. \& Mayer, J. (1956). Amer. F. clin. Nutr. 4, 37.

Kennedy, G. C. (1950). Proc. roy. Soc. B, 137, 535.

Kennedy, G. C. (1953). Proc. roy. Soc. B, 140, 578 .

Mayer, J. (1957). Bull. N.Y. Acad. Med. 33, 744.

McCance, R. A. (1953a). Lancet, 265, 685 .

McCance, R. A. (I $953 b$ ). Lancet, 265, 739 .

Miller, N. E., Bailey, C. J. \& Stevenson, J. A. F. (1950). Science, 112, 256.

Nutrition Society (1956). Proc. Nutr. Soc. 15, 72-99.

Orr, J. B. \& Leitch, I. (1938). Nutr. Abstr. Rev. 7, 509.

Passmore, R. (1956). Proc. Nutr. Soc. 15, 83.

Richter, C. P. \& Wang, G. H. (1926). F. Lab. clin. Med. 12, 289.

Stunkard, A. (1958). Psychosom. Med. 20, 366.

Stunkard, A. (1960). Amer. F. clin. Nutr. 8, 595.

\section{The effects of the endocrine system on calorie balance in man}

\section{By Raymond Greene, io6 Harley Street, London, $W$. I}

I don't know when the endocrine system was first saddled with the blame of obesity. The Chairman, who is an historian as well as a biochemist, may be able to tell us. When I was young, eminent physicians were often heard to speak of 'the pituitary' or 'the thyroid type' of obesity. Even today it is common for members of my profession to treat obesity with weird mixtures of tissue extracts containing those from the pituitary (which, remember, have no action when taken by mouth) and from the thyroid (which may or may not have some activity according as the patient has or has not a deficient secretion of thyroid hormone). I have, indeed a suspicion that thyroid hormone, in doses too small to affect calorie needs, may stimulate the appetite and increase the weight of the patient: the letter beginning 'Mrs So-and-So must have something wrong with her endocrine system. I have given her $2 \mathrm{~g}$ of thyroid a day, but her weight has increased even faster than before' seems to reach me with a frequency that might well be statistically significant.

I will therefore say that there is no good evidence that deficiency of any endocrine gland is an important cause of obesity. That deficient or excessive action may occasionally be a contributory factor is a possibility I propose now to discuss.

The posterior pituitary. This gland has undoubtedly a considerable influence on water balance and thus on body-weight, but its influence on calorie requirements is less well defined. Indeed all that is known is that in rabbits and rats the injection of 
posterior-pituitary extracts appears to affect the localization of fat, for in these animals fatty infiltration of the liver may occur to such an extent that the organ is doubled in size. There is no evidence at present that any alteration in posteriorpituitary activity in man has any such effect.

The anterior pituitary. The anterior pituitary is anyhow historically interesting. This particular stumbling block was laid at our feet by Fröhlich (rgor) who 60 years ago described a patient with a pituitary tumour, who in consequence developed progressive visual failure, due to pressure of the tumour on the optic chiasm, obesity and hypogonadism. It was assumed that the obesity was, like the hypogonadism, the direct effect of pressure on the remaining normal pituitary tissue. It is now realized that it was not so. The obesity was caused by upward pressure by the tumour on the hypothalamus. It is interesting to observe that this particular tumour was successfully removed by Erdheim in 1904 (see Bruch, 1939), and especially interesting at the present day, when pituitary ablation by several different methods is a fashionable subject of discussion in connexion with the treatment of metastatic carcinoma of the breast. The anterior pituitary has also been incriminated as the site of the cause of Dercum's disease (a disease in which the patient develops painful symmetrical deposits of fat) the very existence of which as a nosological entity is now in doubt. Obesity is common but not invariable in Cushing's disease. Some cases of this disease may be due primarily to a pituitary disorder, hyperpituitarism, which affects the body-weight not directly but by producing an excessive activity of the adrenal cortex. In known cases of hypopituitarism, obesity is not a constant feature. The patient with Simmonds's disease or Sheehan's disease may be slightly overweight because of secondary hypothyroidism, but obesity is never seen. Indeed, until recently there was no reason whatever to connect the anterior pituitary with obesity. The work at the Middlesex Hospital, which Dr T. M. Chalmers will doubtless describe in the next paper, may cause us to modify this view.

The thyroid. This gland comes nearer to the mark, though here too clinicians have been tempted into excessive therapeutic optimism. It is unnecessary in this Symposium to repeat all the known facts about the influence of the thyroid on metabolism, but I would remind you that the hyperthyroid patient may need as much as ro $000 \mathrm{kcal}$ a day to maintain body-weight, whereas the hypothyroid patient may be able to maintain it on as little as $500 \mathrm{kcal}$ a day. But hyperthyroid patients are not invariably thin, because their appetites are increased, and hypothyroid patients are not necessarily fat, because their appetites may be reduced. Patients with Graves's disease and normal weight are common and those with slight adiposity are not uncommon. Thyroid function in patients with anorexia nervosa is usually extremely low, but they are invariably emaciated. Several relevant experiments have been conducted on animals. Mackay \& Sherrill (I94I) observed the effects of an equal diet on two groups of rats, one normal and one of animals whose thyroids had been removed. Those with thyroids gained $193 \mathrm{~g}$ in a year, those without $178 \mathrm{~g}$. The bodies of the former contained $31 \%$ of fat, of the latter $6.4 \%$. But the rats without thyroids looked just as plump, presumably because of water retention. Plummer (I940) studied 200 myxoedematous patients. There was no $20(1) 6$ 
significant difference between their weights and those of normal controls and no correlation between the basal metabolic rate (B.M.R.) and any excess of weight. It was, however, observed that when the patients were given thyroid the weight of those whose B.M.R's were lowest dropped more than the weights of those with higher B.M.R's, owing to greater fluid loss. It must be remembered, however, that the estimation of B.M.R. is not strictly a measurement of thyroid activity. It is what it claims to be, a measurement of the metabolism of the patient at the time of the test. Many factors other than thyroid activity may influence it, and it is important to avoid confusing hypometabolism with hypothyroidism. The measurement of B.M.R. has been elevated into an article of faith, because until recent years it was the only means by which metabolism (and hence thyroid activity) could be given a numerical value. In practice it has always been valueless except in the hands of an expert, even as a measure of the oxygen consumption of the patient in a state of rest. Apart from the fact that it is not, by itself, an index of thyroid activity, it is irrelevant to our problem today because people with normal B.M.R's have widely different total daily expenditures of energy. Not only have they different jobs (as is well recognized); but they also put different amounts of energy into their jobs. Two typists with the same B.M.R. do not necessarily expend the same amount of energy throughout the day. Moreover as my team at New End Hospital has recently shown, working in collaboration with $\mathrm{Dr}$ O. G. Edholm's colleagues at the National Institute for Medical Research, two patients with the same B.M.R. do not necessarily expend the same amount of energy throughout the night. Some fat women hibernate at night. The whole question of the influence of the thyroid on calorie needs is due for reconsideration.

The adrenals. Patients with Addison's disease are invariably thin and patients with Cushing's disease are usually fat. When adiposity is associated with an adrenal tumour, it responds badly to dietetic treatment before operation, but normally afterwards. Intestinal absorption may come into the story, but the most important factor appears to be the deficiency or excess of glucocorticoid secretion. The glucocorticoid hormones regulate gluconeogenesis, the production of carbohydrate from protein and fat. If produced to an excessive extent, carbohydrate is in excess of the immediate need and is stored as fat. This storage is probably the cause of the obesity in patients with Cushing's syndrome as well as in those children suffering from what has been named by Simpson adipose gynism in girls and adipose gynandrism in boys. Children suffering from this disorder appear to me to be suffering from a mild and often transient form of Cushing's syndrome.

The gonads. Corpulence traditionally follows castration. In fact the sequence is not invariable, but it is sufficiently important in agricultural economy to have led to the large-scale implantation of stilboestrol into cockerels and to the tastelessness of the modern 'broiler'. It was formerly believed that the corpulence of castrates and of post-menopausal women was due to their reduced physical output of energy and to a transfer of interest from one function that increases energy output to one that increases energy intake. In the words of John Gay 'In youth lip to lip, in old age lip to glass'. My view is that this is too facile an explanation, but I am unaware of any 
recent research throwing light on the question. I admit that I have not explored the recent literature and $I$ hope that if more information is now available I shall learn of it in the discussion.

Perhaps I should briefly draw attention at this point to the fluctuations in weight that normally occur during the menstrual cycle. In the normal woman the temperature in the luteal phase, between ovulation and menstruation, is somewhat less than a degree higher than in the follicular phase, between the beginning of menstruation and ovulation. The rise in the luteal phase is due to the secretion of progesterone, and perhaps more specifically to the increase in production of its metabolite aetiocholanolone. It is accompanied by a rise in weight, in most women of a $\mathrm{kg}$ or so, but in some sufferers from the premenstrual syndrome of as much as $5 \mathrm{~kg}$. This increase is undoubtedly due chiefly to retention of water: it is accompanied by oliguria and corrected during menstruation by diuresis. In some women it is associated also with hypoglycaemia. It may be that this together with the rise in temperature, presumably accompanied by increased calorie requirements, has an exaggerated effect upon the appetite, for one meets occasionally women whose increase in weight is not entirely corrected by the diuresis of menstruation. They seem to add a little to their weight in each menstrual cycle, and this increase can only be prevented by rigid dietetic restriction.

The pancreas. The relationship between diabetes mellitus and obesity has been discussed at great length by many disputants over many years. Its interest to students of nutrition is enormous, but I do not think that it falls within the boundaries of this paper. The old French physicians, who were the first to focus attention on the clinical entity they called diabète gras, believed that this type of the disease was the punishment for gluttony. The endocrinopathy is probably the result of an excessive calorie intake, the opposite subject to that under discussion. But I cannot refrain from stressing the importance of treating seriously any case of obesity occurring in a family with a diabetic tendency. The slim members of such families are less liable to show their genetic weakness than the fat. Perhaps the nutritionist always remembers this: the doctor certainly does not.

I have had to skate very rapidly over these aspects of the problem, omitting a great deal that may ultimately prove to be important. Nevertheless, I would not like to create an exaggerated view of the importance of the endocrine system in the problem. Indeed as I wrote this I became more and more certain that the opposite subject would be more interesting and that my paper should really have been concerned with the influence of nutrition on the endocrine system.

\section{REFERENCES}

Bruch, H. (1939). Amer. F. Dis. Child. 58, 1282.

Fröhlich, A. (I901). Wien. klin. Rdsch. I5, 883 .

Mackay, E. M. \& Sherrill, J. W. (I94I). Endocrinology, 28, 5 r8.

Plummer, W. A. (1940). Trans. Amer. Ass. Stud. Goiter, p. 88. 